\title{
Connectivity at Work: Looking at a Spiritual Model to Improve Relationships at Work and Integrate Spiritual Tenants into Business Processes
}

\author{
Lynette Reed ${ }^{1}$, Trey Fitch $^{2}$ \\ ${ }^{1}$ WEMR, Texas, USA \\ ${ }^{2}$ Troy University, Panama City, USA \\ *Correspondence: Lynette Reed, expectations2reality@icloud.com
}

\begin{abstract}
With the COVID pandemic impacting our current business networks, discussing spirituality in the workplace has become the forefront of how we do business. The need for human connectivity in current times plays an even more significant role in the makeup of how people work. Workplace spirituality is a reasonably new paradigm that has gained an amplified interest in the past two decades with academics and the corporate world [1]. Blau [2] has advocated that even before COVID, social exchanges could create an enhanced work dynamic by suggesting that companies are concerned with material gain and nonmaterial social experiences such as humanitarian ideals and spiritual values. Burack [3] suggested that there has been a rapid growth of spirituality in the workplace and organization in recent times as we have increased social chaos. This growth is mainly because of the changing nature of work and the realization that employees' spiritual level has been neglected for many years [4]. The current challenges have only accelerated the interest in spirituality as a workplace practice. This article will explore recent definitions of spirituality as they relate to religion and counseling in the workplace. Since spirituality is an abstract expression of self, it is not easy to define in its entirety. The paper's focus will converge on a review of the point of view of spirit that gives way to spirituality as defined through the lens of individuals and organizations' relationship to self and others and the world. With the current struggles related to the pandemic and changing times, the integration of spirituality at work can enhance people's connectivity within a business. According to Chopra [5], both leadership and spirituality have a powerful influence on an organization's overall performance. As we continue to move forward into the post-pandemic, the need to have a strong sense of spirit will continue to grow. The article will then introduce three identified behaviors that create a robust spiritual interconnectedness model that can play a role in a business's effectiveness. This spiritual model is introduced to improve relationships at work and integrate spiritual tenants into business processes.
\end{abstract}

Keywords: Connectivity, Work, Spiritual model, Business

\section{ARTICLE INFORMATION}

Author(s): Lynette Reed, Trey Fitch

Received: 06 Feb, 2021; Accepted: 19 Mar, 2021; Published: 12 Apr, 2021; e-ISSN: 2347-4696;

Paper Id: BMN-IJBMR-2021-20;

Citation: doi.org/10.37391/IJBMR.090202

Webpage-link:

https://ijbmr.forexjournal.co.in/archive/volume-9/ijbmr-090202.html

\section{INTRODUCTION}

Human connectivity is an essential aspect of any business. Ashmos and Duchon [6] suggested that there is increasing evidence that a significant transformation occurs in many organizations. With society's changes, especially related to technological advances and the global pandemic, individuals' interactions take on a more significant meaning for a business's success. The connectivity of people intersects with the disconnection of employees.

During this time of revolutionary transition, work is also more integrated with home life. People are spending more time at work. As association in other societal organizations, such as family and civic organizations, is diminishing, people view the workplace as the primary source of connection with other people [7]. In this context, there is a value-added to organizational effectiveness when people feel engaged.
Businesses are looking toward new ways to keep employees connected to work and with each other concerning workplace effectiveness.

The changes in the social, economic, and environmental conditions have decreased the feelings of love and compassion among people, which increases the disconnections of human interactions. According to Cacioppe [8], this shift has triggered a renewed search for harmony and peace, a search that could be considered a spiritual journey. Workplace spirituality is emerging as one of the most significant trends [9]. Employees are looking for something more vital than themselves. They want to understand their role in the broader context [10].

According to Zare \& Beheshtifar [11], spirituality is a way of expressing our desires to find out meaning and purpose in our lives. Pfeffer [12] suggested that workforces are looking forward to living an integrated life, where the work-life is in accord with the employee's essential nature and desire to live as a human being. Stewart, in a recent survey completed by the Torrance, California-based human resource strategists Act-1, found that " $55 \%$ of the workers polled, consider spirituality to play a significant role in the workplace. Also, more than a third of that number $(34 \%)$ said that the role had increased since September 11, 2001, terrorist acts" (p. 92). 
This search for workplace meaning increases as there is more chaos in life. Spirituality becomes a way to balance the instability of the unknown in a world that is fractured. Workplace spirituality is a solution to several complex situations relating to demoralization, feeling alienated from work, and distrusting the employers [13]. Samul [14] found, in a cluster analysis of 373 articles on spiritual leadership that spirituality was the most frequently discussed topic as it relates to work, values, commitment, and culture.

The challenge with spirituality in the workplace stems from the lack of a mainstream format to define spirit. There are many different views of spirituality and how it relates to human connectivity. Spirituality has been closely aligned with religion and counseling to find meaning and comfort, especially in times of chaos. This article focuses on defining relationships between spirit, counseling, and religion, then bringing focus to spirituality from the context of people's connectivity within the workplace. Based on this identification of spirit at work, a new model for introducing spirituality into the workplace will be introduced to create a starting point for integrating spirit into work.

\section{SPIRITUALITY AND WELLNESS}

Leaders in mental health and wellness have also highlighted the importance of aligning thoughts, feelings, and actions. Humanistic theories, in particular, empathize with this concept. Rogers $[15,16]$ called this alignment congruence and concluded it was a central component of mental well-being. Incongruence occurs when people feel reticent in expressing themselves authentically. They communicate ideas and beliefs that conform to societal expectations while hiding their true feelings. People act in ways that contradict their principles or beliefs to gain acceptance from others. Rogers believed that people could facilitate congruence by creating accepting environments and empathy towards others [15]. Accepting environments allow for disagreement without contempt or detachment.

Another pioneer in Humanistic counseling, Fritz Perls, addressed the problem with aligning thoughts, feelings, and behaviors by using Gestalt Therapy [17]. In Gestalt Therapy, people are encouraged to heighten awareness of internal reactions to what is happening in the external world. For example, at a lunch meeting, some people might be too loud and may be perceived as obnoxious, while someone else might be too timid and seems aloof. Gestalt therapy teaches people to be keenly aware of external cues such as other people's reactions and internal signals such as tension or anxiety. Individuals can alter these reactions to respond more authentically $[18,19]$.

Adler $[15,20]$ framed congruence by exploring a person's selfideal compared to a person's self-concept. Mental health wellness occurs when the self-ideal and the self-concept converge closely and are well-aligned. Obstacles to our ideal self can be internal or external. A faulty mindset and distorted perceptions can internally impede our progress. Furthermore, external family dysfunction and negative societal influences can block movement to the self-ideal. According to Adler, encouragement is the key to keeping moving towards the ideal self and encouraging leaders to acknowledge effort and success while providing growth resources. This approach highlights the foundation of Humanistic models that a supportive environment leads to growth [21].

Businesses and organizations can benefit by intentionally fostering congruence in the workplace. Motivation and growth will be positively impacted when people are authentic and feel supported. Humanistic psychology provides a valuable framework for leaders to promote personal growth and wellness by addressing internal and external factors.

\section{SPIRITUALITY AND RELIGION}

There has been a long-standing integration of religion and spirituality. One role of religion was to serve as a portal for spiritual experiences without structure or limitation. The suggestion was made that spirituality and religion could be seen as integrated activities that offer a set of guiding principles for everyday practices and relationships [22]. Integration of the two has also been identified in the context that "Religion is extremely effective at developing spirituality because it provides a framework of meaning, values, and connections to a like-minded community and something greater than self" [23].

Though often interactive, religion and spirituality have been differentiated. In recent times religion has been identified as institutional elements of a belief system that include church membership, church attendance, and adherence to the belief system. On the other hand, spirituality includes experiences related to personal transcendence and meaningfulness [24]. Guillory [25] considered that to distinguish between spirituality and religion, and spirituality becomes the central point that gives rise to performance-oriented activities that serve the individual's best interest and organization.

In contrast, religion is an expression of spirituality that manifests in rules for living, rituals, and structure. The degree of interaction with others is how spirituality plays its intended role in workplace performance, productivity, and profitability.

For many in business, there is often confusion between spirituality with religion [26]. However, Mitroff and Denton [27] found, in a study of spirituality in the workplace, that H.R. executives and managers differentiated between religion and spirituality. They identified religion as a highly inappropriate form of expression and topic in the workplace. These participants defined spirituality as connected to one's complete self, others, and the entire universe. Those associated with organizations identified as "more spiritual" were also viewed as "more profitable." Baunsgaard [28] suggested that the distinction between spirituality and religion is best defined from the book Ancient Wisdom, Modern World: Ethics for the New Millennium by The Dalai Lama:

"Religion I take to be concerned with faith in the claims of one faith tradition or another, an aspect of which is the acceptance 
of some form of heaven or nirvana. Connected with this are religious teachings or dogma, ritual prayer, and so on. Spirituality I take to be concerned with those qualities of the human spirit-such as love and compassion, patience, tolerance, forgiveness, contentment, a sense of responsibility, a sense of harmony-which brings happiness to both self and others."

Current trends seem to suggest a more overall perspective of spirituality being a stand-alone aspect of our human experience related to self, others, and the world.

\section{SPIRITUALITY AS RELATED TO SELF, OTHERS, AND THE WORLD}

Spirituality is considered an elusive activity that ties the mystery of universal connectivity beyond the emotions and activities we perform. Krishnakumar and Neck [29] argued that there are different definitions for the meaning of spirituality due to the powerful personal nature of the word itself. We are looking for ways to connect ourselves with an internal barometer that maintains our true nature with the challenges of emotions and life experiences. According to Conger [7], it is the spirituality that actualizes our true self as it explains our emotions, explores our inner strengths, and identifies what we are deep down and how much we are divinely blessed, evidently calling it as the knowledge of the heart. Spirituality from the focus of connectivity might also be explained as an existential and experiential focus upon an individual's internalized faith, values, and beliefs along with the consequences in daily behavior [30]. So, spirituality is commonly observed as some core element, a belief, emotion, value, or attitude that affects one's behavior. Based on these attempts to define the role of spirituality with the framework of connectivity, the word spirit's root might shed some light on the relationship of spirituality to connectivity.

Current events and global connectivity are changing the way we work. Businesses, many times, focus on the overarching issues facing the workplace but do not integrate spirit. "Though we have solutions for economic, technological, and political problems, emotional breakdowns, inner voids, and ethical and moral transgressions are challenging humanity. Amidst this, one of the world's hopeful developments is a revival of interest in spirituality and a mystical quest. People who have had spiritual experiences show distinct changes in their psyche, their approach toward fellow beings and life, representing a movement away from destructive personality characteristics and emergence of values fostering individual and collective survival. The individual experience of engagement at work is promoted when employees feel empowered to accomplish their work in a meaningful way." [31].

This change holds the potential for a major transformation of the hostile world that one is increasingly confronting [32]. Goleman [33] suggested that organizations can no longer neglect the employees' human abilities and emotions. Mohamed, et al. [34] approached spirituality from the managerial and psychological perspectives. From a managerial view, spirituality can be seen as the, 1) simple feeling of being connected with one's self, others, the transcendental, and the universe; 2) a work feeling that energizes action; 4) values aimed at transcendence toward ultimate values; 5) the deeply held values that guide life and work practices; 6) the identification of an inner life that nourishes and is improved by meaningful work in the context of community, and 7) the way to achieve personal envisioned growth. This behavior supports the idea that there is an inner life nourished and nourished by meaningful work in the community context [6]. From this perspective, spirituality may be a value-added to businesses to strengthen workplace connectivity. Hillard [35] asserts a view that spiritual grounding provides the roots for most organizational activities, decisions, and practices. Spirituality is the foundational element of a thriving work community. Spiritual practices can align individuals and organizational values for business success [36-38]. The proposed view that high productivity, stakeholder's reliance, and commitment endurance is a way to work spirituality to become feasible but only when organizational cultural values and its theoretical aspects match employees' potentials and spiritual connotations. Spirituality in this aspect encompasses each personal spiritual experience with the cumulative spiritual experience of the organization.

As Singh [39] suggested, "Spirituality is not a one-shot affair; it's not an end but an ongoing process. It is more concerned with the ways by which a goal is achieved rather what has been achieved. There is a need for spirituality in order to develop employee and build on creativity to achieve organizational goals. But the rate at which an organization grows is not fixed and same for everyone. Every individual has its own pace and more of self-determination."

Referenced as workplace spirituality for the cumulative experience, has been defined as "a framework of organizational values evidenced in the culture that promotes employees' experience of transcendence through the work process, facilitating their sense of being connected to others in a way that provides feelings of completeness and joy" [40].

\section{MODEL FOR SPIRITUAL DEVELOPMENT TO STRENGTHEN INDIVIDUALS AND BUSINESSES}

In the book, Fixing the Problem, Making changes in how you deal with challenges [41], a model for spirituality was outlined based on the concept of spirituality related to its core meaning of breath and inspire. This process puts a set of behaviors that utilize each person's highest potential in a changing world based on spiritual practices that bring more robust connectivity to individuals and the organization. Spirituality is not a quick fix for problems but rather a process to connect individuals within a world where other people and events influence business. Spirit "is not a physical thing that you can see or touch but is the essence of who we are as individuals. It is our human potential. Life events toss our spirit around a bit. People often do not recognize their spirit or the spirit of others." [41]. 
This model's follow-up submits that this lack of recognition causes much of the harm we see in the world. So, when looking at spirit from its root meanings of breath and inspire, spirit would occur with every breath while deciding how to live life. With each breath, there is the opportunity to become inspired by the connection to self, other people, and the world. At that moment, there is the ability to strengthen or fracture this connectivity. When spirit is approached from this perspective, then it has the potential at any moment in time to strengthen or fracture the inner workings of individuals, their interpersonal relationships, or the system of a business or organization. This section of the article outlines the basic model [41] for introducing spirituality into a workplace setting to increase engagement, improve communication, and strengthen culture.

\subsection{Personal Intentional Mission Statement}

These are words that define how a workplace team can achieve more excellent connectivity. The PIMS words are adjectives that identify how individuals will talk with each other, especially in difficult situations. The PIMS measure of success on this element comes from how well the team members use these behaviors to handle daily situations. The group defines these words as a whole since everyone has a slightly different definition of a word. For instance, if the word is friendly, the focus would include discussing what friendly means to them.

For some individuals, friendly might mean to smile and help each other out. For other team members, being friendly might be considered taking time to talk with someone. Having a clear definition of the differences and variety of thought is vital to maintaining an integrated workplace. A shared vocabulary about how to exist with each other increases connectivity among individuals. For some people, this will be intuitive. For others, a practice may be necessary in order to establish this form of behavior.

\subsection{Words and Actions Match}

Individuals and groups build trust and authenticity when words and actions match. When there is a divergent action to a word, then the system of connectivity becomes fractured. For instance, if an individual on the team states they are helpful, but does not choose to take actions that help other individuals, then alignment of core life elements with observable behavior diverges, causing a loss of trust. When identified from breath or inspired, this element of spiritual connectivity finds a breakdown in the choice to remain connected or fracture the event at the moment. These interactions are also helpful in diversity and inclusion because success is how well, a person integrates into the team's words.

\subsection{Do Not Judge as Good or Bad or Wrong or Right}

Connectivity relates to a sense of self. Individuals who feel they are doing a bad job tend not to integrate into a system effectively and may lose value with the team. Individual who feels bad or wrong when they make a mistake will feel devalued due to the label. In this system, individuals' connectivity might be considered good, and some are bad. Other individuals might be perceived as right, and some are wrong. In the spirit of breath, there is no good or bad, or wrong or right. The judgment of individual value pulls people backward and looking for people to blame. A group that recognizes the inherent value of all group members finds a greater sense of stability. They can move forward, trying to find a solution and fix problems. These three behaviors work together as a system of connectivity for individuals at work and in teams. With spirit as breath and inspire the goal is to find long-term solutions to situations that keep connectivity healthy.

\section{CONCLUSION}

As rightly pointed out by Martin and Cullen [42], promoting a climate of trust in the organizational environment depends on adherence to a set of rules and principles of conduct, which advocates ethical values shared by the company's members. Based on the information reviewed in this article, there is a place for spirituality in the workplace related to the definition of spirituality as our connection to self, others, and the world.

Although related to religion and counseling, spirituality can act as a stand-alone system that enhances individuals' interconnectedness with a business setting. With the use of its core elements of breath and inspire, spirituality allows businesses to strengthen the human element of any individual or group of people. This connectivity can have far-reaching effects on work elements related to conflict resolution, critical thinking, and even sustainability or resiliency. The major limitation of spirituality is that the nature of the discussion is primarily theoretical. The researchers' goal is to conduct empirical research to add validity to the discussions on the value of spirituality in the workplace. Future research should identify additional dimensions of workplace spirituality, especially when including them in the current framework.

\section{REFERENCES}

[1] Houghton, J. D., Neck, C.P., \& Krishnakumar, S. (2016) The what, why, and how of spirituality in the workplace revisited: A 14-year update and extension. Journal of Management, Spirituality \& Religion, 13(3): 177-205.

[2] Blau, Peter M. (1964) Exchange and power in social life. New York, US: Wiley.

[3] Burack, E. (1999) Spirituality in the workplace. Journal of Organizational Change Management, 12: 280-292.

[4] Parumasur, S. B., \& Govender, P. (2016) Empirical study on the link between corporate citizenship behaviour and spirituality in the corporate environment. Risk Governance \& Control: Financial Markets \& Institutions, 6(3): 81-92.

[5] Chopra, D. (2002) The soul of leadership. School Administrator, 59(8): 10-12.

[6] Ashmos, D. P., \& Duchon, D. (2000) Spirituality at work: A conceptualization and measure. Journal of Management Inquiry, 9 (2): 134-145.

[7] Conger, J. (1994) Spirit at work: Discovering the Spirituality in Leadership. San Francisco, US: Jossey-Bass. 


\section{Business and Management Research (IJBMR)}

Review Article | Volume 9, Issue 2 | Pages 113-117 | e-ISSN: 2347-4696

[8] Cacioppe. R. (2000) Creating spirit at work: Re-visioning organization development and leadership-Part 1. Leadership and Organization Development Journal, 21(2): 48-54.

[9] Shellenbarger, S. (2000) More relaxed boomers, fewer workplace frills and other job trends. Wall Street Journal.

[10] Strack G., Fottler M. D., Wheatley, M.J. \& Sodomka, P. (2002) Spirituality and effective leadership in healthcare: Is there a combination? Frontiers of Health Services Management, 18(4): 3-17.

[11] Zare., E., \& Beheshtifar, M. (2013) Effect of spirituality in workplace on job performance. Interdisciplinary Journal of Contemporary Research in Business, 5: 248.

[12] Pfeffer, J. (2003) Business and the spirit. In: R. A. Giacalone \& C. L. Jurkiewicz (Eds.), Handbook of workplace spirituality and organizational performance. M. E. Sharpe, Inc. pp. 29-45.

[13] Ali, H., \& Falcon, M. A. (1995) Workplace spirituality: A spiritual audit of banking executives in Pakistan. African Journal of Business Management, 6 (11): 3888-3897.

[14] Samul, J. (2020) Spiritual leadership: Meaning in the sustainable workplace. Sustainability, 12: 267-270.

[15] Corey, G. (2016) Theory and practice of counseling and psychotherapy. Belmont, CA, US: Brooks/Cole.

[16] Rogers, C. (1951) Client centered therapy. It's current practice, implications, and theory. Boston, MA: Houghton Mifflin.

[17] Fitch, T. J., Marshall, J., Matise, M., McCullough, G. (2020) Introduction to counseling. London, UK: Routledge.

[18] Cain, D. J. (2010) Humanistic psychotherapies. In: I.B. Weiner and W.E. Craighead (Eds.), The Corsini Encyclopedia of Psychology. Wiley and Sons Inc. p. 785.

[19] Perls, F. (1969). Gestalt therapy verbatim. Lafayette, CA, US: Real People Press.

[20] Ansbacher, H. L., \& Ansbacher, R. R. (Eds.). (1956) The individual psychology of Alfred Adler. New York, US: Basic Books.

[21] Carlson, J., Watts, R., \& Maniacci, M. (2006) Adlerian therapy. Theory and practice. Washington DC, US: APA.

[22] Azouz, A., Antheaume, N., \& Charles-Pauvers, B. (2021) An ethnography of fairness perceptions among non-family employees: Does religion matter? Journal of Family Business Strategy.

[23] Top, J. (2019) Spirituality: The core of leadership. Marine Corps Gazette, 103(8): 66-69.

[24] Hill, P. C., Pargament, K. I., Hood, R.W., McCullough, J. M. E., Swyers, J. P., et al. (2000) Conceptualizing religion and spirituality: Points of commonality, points of departure. Journal for the Theory of Social Behaviour, 30(1): 51-77.

[25] Guillory, W. (2017) Spirituality in the workplace. The way of the heart.

[26] Brandt, E. (1996) Corporate pioneers explore spirituality. HR Magazine, 41: 82-87.
[27] Mitroff, I. \& Denton, E. A. (1999) A study of spirituality in the workplace. MIT Sloan Management Review, 40: 83-92.

[28] Baunsgaard, V. (2019) Workplace spirituality: Why \& how it works like a charm. Manage Magazine.

[29] Krishnakumar, S. \& Neck, C. P. (2002) "The“what", "why" and "how" of spirituality in the workplace. Journal of Managerial Psychology, 17: 153-164.

[30] Moberg, D. O. (2008) Spirituality and aging: Research and implications. Journal of Religion, Spirituality, \& Aging, 20: 95134

[31] Cooper, C. L., \& Leiter, M. (2017) Wellbeing at work. New York, US: Routledge.

[32] Sharma, P., Charak, R., \& Vibha, S. (2009) Contemporary perspectives on spirituality and mental health. Indian Journal of Psychological Medicine, 31(1): 16-23.

[33] Goleman, D. (1998) Working with emotional intelligence. Soho Square, London, UK: Bloomsbury Publishing.

[34] Mohamed, A. A., Wisnieski, J., Askar, M., \& Syed, I. (2004) Towards a theory of spirituality in the workplace. Competitiveness Review, 14: 102-107.

[35] Hillard, J. C. (2004) Inspired by the golden rule: Business ethics titles bring religions principles into the workplace. Publishers Weekly, 21: 12.

[36] Dushon D., \& Plowman, D. A. (2005) Nurturing the spirit at work: Impact on unit performance. The Leadership Quarterly, 16(5): 807-834.

[37] Fry, L. W. (2005). Toward a theory of ethical and spiritual wellbeing and corporate social responsibility through spiritual leadership. In: R.A. Giacalone, C. L., Jurkiewicz, \& C. Dunn (Eds.), Positive psychology in business ethics and corporate responsibility. Information Age Publishing. pp. 47-83.

[38] Malone, P. F., \& Fry, L. W. (2003) Transforming schools through spiritual leadership: A field experiment. Paper presented at the Academy of Management, Seattle, WA.

[39] Singh, S. (2019) The impact of workplace spirituality on employees' productivity and their wellbeing. The Global Journal of Enterprise Information System, 11(1): 61.

[40] Giacalone, R. A., \& Jurkiewicz, C. L. (2003) Toward a science of workplace spirituality. In: R. A. Giacalone, \& C. L. Jurkiewicz (Eds.), The handbook of workplace spirituality and organizational performance. M.E. Sharpe. pp. 3-29.

[41] Reed, G. L. (2009) Fixing the problem, making changes in how you deal with challenges. Bloomington, IN: iUniverse.

[42] Martin, K. D., \& Cullen, J. B. (2006) Continuities and extensions of ethical climate theory: A meta-analytic review. Journal of Business Ethics, 69: 175-194.

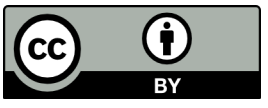

(C) 2021 by the Lynette Reed and Trey Fitch. Submitted for possible open access publication under the terms and conditions of the Creative Commons Attribution (CC BY) license (http://creativecommons.org/licenses/by/4.0/). 